by considerations raised by speakers concerned with the actual technique in its practical application. Thus, even with the necessary density of cow population within reasonable distance, the successful operation of an insemination centre depends upon a satisfactory recognition of the administrative, economic, and technical problems, in themselves and in their inter-relations. For example, if artificial insemination is to be used as a means for milch cattle improvement, a centre must clearly be able to supply semen from proved superior bulls. How can these sires be chosen with sufficient certainty ? Are such bulls available in sufficient numbers and at a reasonable cost ? The cost of inseminations must be made competitive with that of natural services; the results in terms of service efficiency, or conception-rates, must be comparable with natural matings, and those in terms of the performance of progeny must be demonstrably advantageous, so that farmers are encouraged to use the centres. Further, the centres must have definite long-term breeding policies.

A full report of the proceedings will be published. J. E. NTCHOLS.

\section{NATIONAL ACADEMY OF PEIPING AND ITS WAR-TIME ACTIVITIES}

$\mathrm{T}$

HE National Academy of Peiping was founded by the National Government of China on Sep. tember 9, 1929, with Dr. Li Yu-Ying as president and Dr. Li Shu-Hua as vice-president. It consisted originally of nine separate departments, the Institutes of Physics, Radium, Chemistry, Materia Medica, Physiology, Zoology, Botany, Geology, and Historical Studies and Archæology. The new Academy flourished and in a few years had made valuable contributions to many different fields of research. By 1935-36, however, the political situation in the northern provinces of China made necessary the evacuation of several institutes to safer areas. On the outbreak of war in 1937, Peiping was immediately taken over by the Japanese, and the Academy was forced to abandon all its remaining activities there. Despite the confusion, some books and equipment were moved southward and eventually, despite immense practical difficulties, the Academy was able to resume much of its work at Kunming. During the War, the policy of the Academy has been to devote its attention largely, but not exclusively, to the immediate needs of the nation.

In the Institute of Physics research work was originally devoted largely to problems in photography, spectroscopy, piezo-electricity, and geophysics. After the evacuation to Kunming, attention was turned mainly to practical problems, particularly the manufacture of optical instruments. A great variety of optical parts are now produced; 500 microscopes have been built as well as 150 sets of optical parts for surveying instruments. The optical division also repaired apparatus for the American Air Force in Kunming. The Institute prepared 1,000 piezoelectric quartz plates for stabilizing transmission from numerous low-power radio stations established throughout Free China. The Institute's geophysical surveys led to discoveries of great economic importance.

In Peiping the Institute of Radium consisted of three laboratories for studying chemistry, radioacti- vity, and X-rays. The radioactivity of protoactinium was closely investigated, as well as the radioactive and chemical properties of many Chinese minerals. On the outbreak of war, this Institute moved to Shanghai, where work was carried out on the absorption coefficients of $\beta$-rays, certain colour effects of $\beta$ - and $\gamma$-rays on glass, and the analysis of alloys by X-ray methods. When conditions in Shanghai became impossible, Dr. Choong, who had been engaged in spectroscopic investigations, made his way to Kunming and resumed work there, primarily on the fine structure of quartz. The Shanghai laboratories continued to work, under Dr. Lu, but were isolated for more than three years.

Since its evacuation to Kunming, the Institute of Chemistry has largely concerned itself with practical problems such as the extraction of dyes from local plants, the preparation of medicines and the manufacture of industrial alcohol. Time has also been found for some purely academic research, including synthesis of substances related to vitamin $K$ and to rotenone, investigations of pinacol rearrangements, and the study of Grignard compounds and cobaltammine complexes.

Extensive research on Chinese drugs was done before the War at the Institute of Materia Medica, but this was twice interrupted by evacuation, first to Shanghai and later, in part, to Kunming. Dr. Chuang has made notable contributions to the chemistry of hormones, and, despite great difficulties, has continued this work since his arrival in Kunming in 1944. Intensive search has been made for new synthetic antimalarials. Drugs such as ephedrine and vitamin $B_{1}$ have been prepared on a commercial scale.

Before evacuating to Kunming, the Institute of Physiology carried out investigations in experimental biology, cytology, and physiology. At Kunming some applied research was started, but lack of staff compelled the abandonment of all research in 1943 .

The main work of the Institute of Zoology has been ecological studies throughout China. After evacuation to Kunming a detailed study was made of the freshwater fauna, reptiles, and spiders of Yunnan.

The Institute of Botany has worked mainly on the taxonomy of Chinese plants. Since the evacuation to Shensi Province, the work has continued with the plants of north-west China, particular attention being given to plants of economic importance; extensive collecting expeditions have been organised.

While in Peiping, the Institute of Geology cooperated with the Geological Survey of China and made many important contributions to knowledge of China's geological history. One of its best-known discoveries was that of the remains of Sinanthropus pelcinensis (Peking man). Much time was given to palæontological research. In 1935 the greater part of this Institute moved to Nanking. In 1937 a further move was made to Beipei, near Chungking, where, despite these setbacks, extensive field and laboratory studies, particularly of mineral deposits, have been vigorously pursued.

The Institute of Historical Studies and Archæology was formally founded in 1937 from an existing Committee of Historical Studies. Before the War much work of exploration and discovery was carried out in all parts of China, but particularly round Peiping, with fruitful results. Since its evacuation to Kunming, study has largely been confined to ancient Chinese history, the classification of material from excavations in Shensi, and the collection of material relating to aboriginals of regions bordering China. 